\section{A Comment on Formalin Safety}

Dick Dapson, Anatech Ltd. anatechnet-link.net

For several months there have been recurring threads on microscopy-related internet listservers concerning health and safety issues that have troubled us greatly at Anatech Ltd. The general theme has been to make light of toxicity claims, provide anecdotal comments about having survived many decades of working in labs, and giving the impression that current health and safety regulations are at best a pain and probably are the cunning products of misguided governmental agencies.

The great hazard of formaldehyde is not its proven carcinogenicity. Anyone interested in formaldehyde's effects on humans should read the preamble to OSHA's Formaldehyde Standard (Federal Register 52(233):46168-46312; December 4,1987 ). According to studies cited therein, formaldehyde has been directly implicated in causing tumors in the lungs, nasoand oro-pharynx and nasal passages of humans occupationally exposed to levels of formaldehyde not unlike conditions existing in histology laboratories a few decades ago. Repeated and prolonged exposure increases the risk.

True, the risk is small, and with the improved ventilation in most US labs (at least), one could justify ignoring the issue altogether. I personally do not care to increase my risk, but the significance is truly minor.

However, Formaldehyde presents a vastly greater risk to people working with it by being a potent sensitizer. Once sensitized, people will probably experience worsening symptoms for the rest of their lives even if they leave the field. Formaldehyde cannot be avoided. It off-gasses from most building products except untreated lumber. It has been widely used in the permanent press treatment for fabrics (although glyoxal is replacing it there as it is in histological fixatives). It comes out of carpeting drapes and upholstery. Sensitized people will get more colds, suffer with them longer, may develop asthma, or experience worsening asthmatic attacks.

OSHA reported in 1982 that $79 \%$ of the histotechnologists studied showed respiratory and dermatological symptoms consistent with formaldehyde-induced sensitization, a 2-fold increase over the control group. Exposure levels for those histotechs were $0.2-1.9 \mathrm{ppm}$, levels that were really rather moderate for the time (pre-1987).

The Formaldehyde Standard was written in great part because of the unacceptable conditions in pathology labs. Industry had long since cleaned up its act. The standard's preamble specifically singles out pathology labs as being among the worst for workplace exposure.

Perhaps many readers do not remember or were not in the field before 1980. A few techs were concerned about chemical exposures, but were mostly stymied by glib administrators and uncaring co-workers whose attitudes were strikingly like those being aired on microscopy listservers today. The National Society for Histochemistry struggled many years to bring these concerns to light, organizing a Health \& Safety Committee, sponsoring studies of formaldehyde and xylene exposure, providing workshops and lectures on all aspects of health and safety, and compiling lists of resource materials and personnel. The real leaders of this field have taken the subject very seriously. Please don't go back down that road in reverse; if you do, do it alone.
Launohing a new product gan be a treacherous journey.

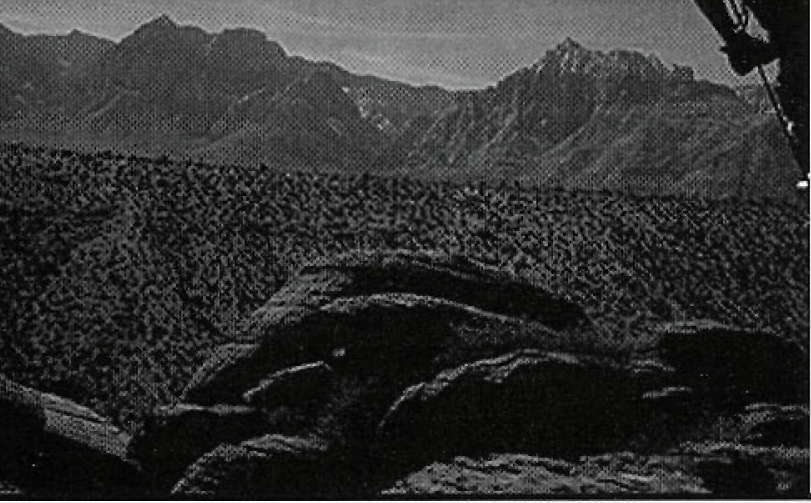

\section{Inspiration is not enough.}

Success requires sound planning, experience, and great execution. If you are wise enough to recognize your organization's weaknesses, but not ready to hire full-time specialists, The Ascend Group may be your answer. We are a global network of professionals offering Sales, Marketing, and Strategic Management services to start-up and emerging technology companies.

\section{Contact us today to find out about our range of available services.}

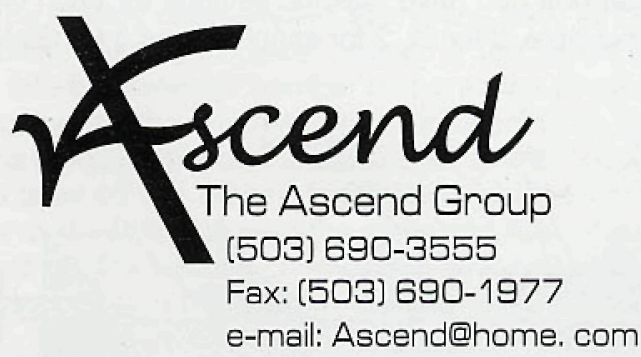

Taking your Business to the Top 
I want to set the record straight. Formaldehyde can be vorked with safely. No one should ever need a respirator. Simple, roperly designed ventilation can easily keep vapor levels below e OSHA Action level of $0.5 \mathrm{ppm}$ averaged over 8 hours. Stay elow that level (and the STEL of 2 ppm over 15 minutes), and eople can avoid almost all of the standard's requirements, and ave a safe workplace, at least for the inhalation of formaldehyde apors.

Skin contact with formaldehyde is another issue altogether. atex surgical gloves offer no protection (breakthrough time is econds to a few minutes). Very thin nitrile gloves are probably larginally better, but breakthrough times are not available. This $\mathrm{rm}$ of exposure is the cause of most modern-day sensitization zactions to formaldehyde. Butyl and nitrile gloves comparable in lickness to dishwashing gloves will protect you for most histoIgical tasks involving formaldehyde (Schope et al., 1987, Guideies for the selection of chemical protective clothing, ACGIH, Cinnnati, $\mathrm{OH})$. Unfortunately, these protective devices, make deliate work difficult.

Making $10 \%$ formalin from $36 \%$ makes economic sense only til labor, overhead and compliance costs are factored in. Coue that with $\mathrm{QC}$ issues and suddenly the commercial product Im a reputable vendor is a lot more attractive. As has been inted out on the microscopy servers, having $10 \%$ formalin ade by a company conforming to Good Manufacturing Practices Id controlled by the FDA goes a long way toward providing rkers with peace of mind that the solution actually does contain $7 \%$ formaldehyde. It can be bought cheaply, but you will get actly what you pay for....as always.

Finally, concerning the assaying of formalin, there are sev- eral methods available but few will provide the specific concentration with a given level of precision and accuracy. Of the latter, only one is feasible for general use (the others require glassware and calibrated standards). Anatech Ltd. and B/R Instruments have an assay kit that unambiguously determines the concentration in increments of 2 percentage units (e.g., 9.0-10.9\%). The test takes a minute or two to perform it is familiar.

Sakura recently came out with test strips, like $\mathrm{pH}$ dip sticks, which are much easier to use but may be difficult to interpret (the color differences between $7.5 \%$ and $10 \%$ are debatable, the colors are transient, and the important color develops in the center of the stick's patch, not the edge, making comparison with the picture difficult).

If safety issues are of concern or interest to you, obtain a copy of our Hazmat Maunal (Dapson \& Dapson, 1995, ${ }^{* *}$ Hazardous Materials in the Histopathogy Laboratory**, 3rd edition, available from Anatech Ltd.). The answer to virtually every health, safety and disposal question that has ever appeared on the HistoNet can be found within its 253 pages.

I could continue with another tiresome page on xylene, but I'll spare you.

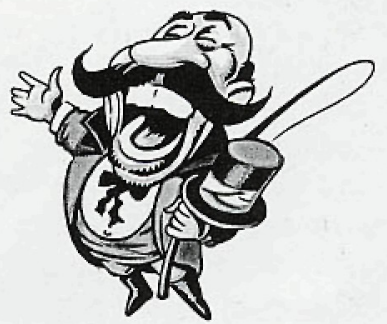

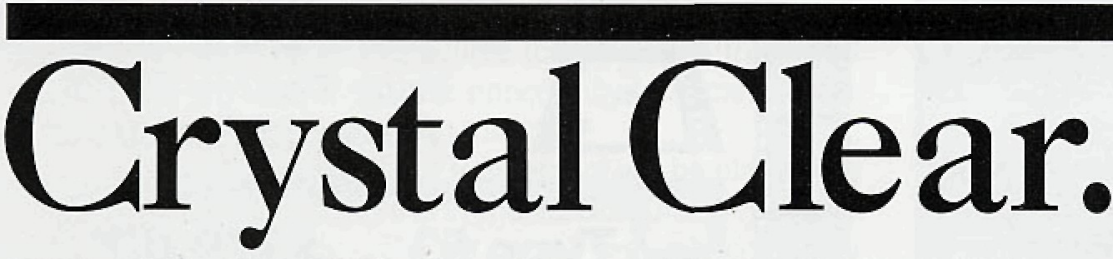

\section{The Meiji EM Series of Modular Stereo Microscopes.}

If you are looking for precision, durability, quality and value in a stereo microscope, we invite you to take a closer look at Meiji's EM Series of Stereo Microscopes.

The modular design (A wide variety of bodies, single magnification or zoom- rotatable $360^{\circ}$, auxiliary lenses, eyepieces, stands, holders, etc.) gives you the freedom to create the ideal instrument for your specific needs or application, and Meiji stands behind every instrument with its limited Lifetime Warranty.

For more information on these economically priced stereo microscopes, please call, FAX or write us today.

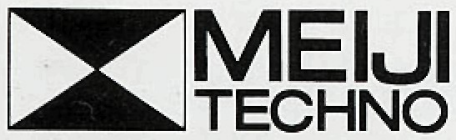

